\title{
THEORETICAL STUDY OF THE NON-WATSON-CRICK BASE PAIR GUANINE-GUANINE
}

\author{
S. TERESA MADARIAGA AND J. GUILLERMO CONTRERAS ${ }^{2}$ \\ ${ }^{1}$ Centro de Docencia Superior en Ciencias Básicas, Universidad Austral de Chile. Sede Puerto Montt. \\ Casilla 1327, Puerto Montt \\ ${ }^{2}$ Facultad de Ciencias Químicas. Universidad de Concepción. \\ (Received: August 7, 2009 - Accepted: November 16, 2009)
}

\begin{abstract}
A theoretical study of the non canonical base pair, Guanine-Guanine (G-G) has been carried out in the frame of molecular orbital theory using density functional theory (DFT). The Becke three parameter hybrid including correlation functional that contains local and non-local terms (B3LYP) was used thoroughly. The 6-31G(d,p) basis set was employed to obtain the optimized geometry and energy of the non-Watson-Crick pair formed between two molecules of guanine. The results compare well with the properties of other base pairs of biological interest. At the DFT level the non-planarity of the pair is evident. The two guanines molecules are bent by ca $12^{\circ}$ and buckled. The interaction energy corrected by BSSE is equal to $-10.7 \mathrm{kcal} / \mathrm{mol}$, similar to that calculated for other pairs involving bases of nucleic acids.
\end{abstract}

\section{INTRODUCTION}

The interaction between nitrogen bases of nucleic acids is a molecular recognition event that has been widely studied ${ }^{1-4}$. The interaction takes place trough extensive hydrogen bonding leading to the canonical pairs: guaninecytosine (G-C), adenine-thymine (A-T) and adenine-uracile (A-U). A base pairing occurring in any other combinations but these given above, conduct to a non-canonical pair formation.

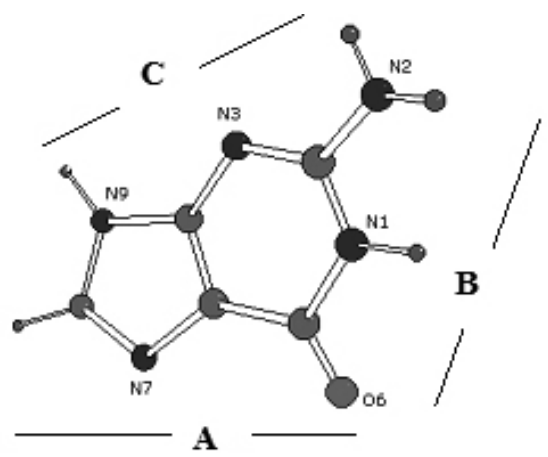

\section{A: Hoogsteen edge} B: Watson-Crick edge C: sugar edge

Fig.1: the interaction edges in Guanine (G)

The study of non-Watson-Crick interactions have great importance because they play an important role in various processes associated with biological functions of RNAs. The presence of these pairs is a key in RNA-RNA interactions and RNA-protein, providing specific sites for drugs, antibiotics and some ions recognition ${ }^{1}$. Meanwhile, in the nuclear DNA the non-WatsonCrick base pair is related primarily to processes of genetic mutation, in RNA is a rather common feature that generates a highly structured nucleic acid very important in the different processes associated to its biological functions. An extensive classification of different types of non-canonical interactions has been given by Lescoute and Westhof ${ }^{5}$ including the cis or trans orientation with respect to the glycoside bond. The guanine capability to form hydrogen bonding with two and three molecules of guanine is interesting in terms of the role of such structures in the genetic expression and their potentiality in genetic therapy. The presence of the non Watson-Crick GG pair in DNA points towards one out of four possible forms of the so called Single Nucleotide Polymorphisms. Two important experimental evidences are relevant to the detection of this kind of mutation. Thus, when the G-G intermolecular interaction occurs between $\mathrm{N} 7$ of the pyrazolinic ring and the exocycle amino group $^{6}$ or some small molecules such as naphthyridine ${ }^{7}$ selectively bond to a GG pair allowing the development of no-Watson-Crick pair sensors within
DNA. Three nitrogen bases interactions are made up of a Watson-Crick pair and a third base leading to a no-Watson-Crick. These DNA-triplexes are related with the main origin of inherited neurological disease ${ }^{8}$. In vitro ${ }^{9}$ studies carried out, for the first time, in 1910 showed the potentiality of guanine to form cyclic structures involving four molecules of such a nitrogenous base. Guanine acts as a donor and acceptor center of two hydrogen bonds. Such interaction takes place between a Watson-Crick edge and a Hoogsteen edge

Guanine quartets in telomeric DNA ${ }^{10,11}$ and more recently in non-telomeric genomic DNA ${ }^{12,13}$ could leads to DNA-quadruplexes formation. These DNA complexes would be of importance in the search of cancer treatment agents ${ }^{14}$. It has been presumed that this type of interactions play important role in blocking telomerase action. Telomerase is present in ca. $85 \%$ cancer cells ${ }^{11}$.

Although, the importance of individual molecular events involving the bases of nucleic acid is clear, the electronic and geometric features associated with them are not so well understood. While the results of multiple investigations about pairing of RNA and DNA bases show that it is possible to establish a relationship between the hydrogen bonding model, structural and geometric configuration and the role that base pairs play inside them ${ }^{4}$, the relationship between the energy of interaction and frequency of occurrence in three-dimensional structures of nucleic acids, is not so clear. Theoretical studies on the interaction energies reveal that the estimates made using ab initio methods with basis set 6-31G (d,p) are suitable for to study isolated bases and their respective pairs ${ }^{15}$.

Accordingly, the results are to be considered as a good approach to the of base pairs behavior. Interaction energies of pairs are in the range of -5 and $-27 \mathrm{kcal} / \mathrm{mol}$, that is, values that correspond hydrogen bonding of two types: i) the polar type $\mathrm{NH} \cdots \mathrm{O}$ or N, and ii) hydrogen bonding of type $\mathrm{CH} \cdots \mathrm{O}$ or $\mathrm{N}$, being the former more stable than the late ${ }^{4}$. This conclusion is consistent in previous studies ${ }^{3}$ and agrees with the frequency with which it is possible to find certain pairs of bases within the nucleic acids. The pair $\mathrm{G}=\mathrm{C}$ is found to be a highly stable interaction with energy equal to $-22.9 \mathrm{kcal} / \mathrm{mol}$ at the $\mathrm{HF} / 6-31 \mathrm{G}$ $(\mathrm{d}, \mathrm{p})$, whereas at B3LYP $/ 6-31 \mathrm{G}(\mathrm{d}, \mathrm{p})$ a value of ca. $-26.51 \mathrm{kcal} / \mathrm{mol}$ has been obtained (Correction for BSSE energy, included in both levels ${ }^{3}$ ). On the other hand, the direction of cis regarding to the glycosidic link are less frequent as well as the interactions among the sides Watson-Crick and Hoogsteen between two pyrimidines or two purines.

In this paper, we present the theoretical study of structural properties, geometry and interaction energy of the Guanine-Guanine pair, whose model of a hydrogen bonding occurs between the Watson-Crick and Hoogsteen edges. The study is based on the methods of theoretical chemistry at ab initio using DFT methods. The optimization of the structures was carried out using the B3LYP functional and basis set type 6-31G (d.p). The energy of interaction was obtained at the same level of theory and corrected for BSSE. The results allow comparing the properties between different models of hydrogen bonding involving the nitrogen bases of nucleic acids and see whether a relationship between the energy of interaction, frequency of occurrence takes place and furthermore the role they play. 


\section{COMPUTATIONAL METHODS}

Standard ab initio calculations, in the frame of molecular orbital theory, were performed using Gaussian 98 suite of programs ${ }^{16}$. Geometry optimization for the Guanine-Guanine pair was carried out by DFT method using hybrid B3LYP functional ${ }^{17,18}$ with the $6-31 \mathrm{G}(\mathrm{d}, \mathrm{p})$ basis set followed of frequency calculations in order to see whether the derived structures yielded are local minima. Frequency calculations indicate that the non-canonical pairs show imaginary frequencies when the angles involving the hydrogen bonding are ca. $180^{\circ}$. The natural pairs G-C and A-T are local minima for angles close to $180^{\circ}$. BSSE (basis set superposition error) corrections were calculated using the counterpoise method (CPM) formulated by Boys and Bernardy ${ }^{19}$. Accordingly, $\mathrm{BSSE}(\mathrm{XY})=\mathrm{E}(\mathrm{X})_{\mathrm{X}}+\mathrm{E}(\mathrm{Y})_{\mathrm{Y}}-\mathrm{E}(\mathrm{X})_{\mathrm{XY}}-\mathrm{E}(\mathrm{Y})_{\mathrm{XY}}$, where $\mathrm{E}(\mathrm{X})_{\mathrm{XY}}$ is the energy of $\mathrm{X}$ calculated at the supermolecule basis set, $\mathrm{E}(\mathrm{X})_{\mathrm{X}}$ corresponds to the energy of $\mathrm{X}$ calculated at its own basis set.

\section{RESULTS AND DISCUSION}

Fig. 2 shows the models of a hydrogen bonding of Guanine-Guanine pair studied. Molecular recognition takes place through the Watson-Crick sides of one Guanine and the Hoogsteen side of the another base and in cis configuration with respect to the atoms $\mathrm{N} 9$ respectively.

The optimized structure of Guanine(I)-Guanine(II) (hereafter abbreviated G(I)-G(II)) shows that the geometric parameters (Table 1) of the bases involved do not change much by pair formation. This result is consistent with the geometric and structural features previously reported by our group ${ }^{20,21}$ The geometric parameters of hydrogen bonds in G(I)-G(II) (Table 2), indicate that the $\mathrm{NH} \cdots . \mathrm{O}$ angle is de179.0 degrees, similar to that found in the pair $\mathrm{G}=$ $\mathrm{C}$, whereas for $\mathrm{NH} \cdots \cdots \mathrm{N}$ the angle is ca. 167.8 degrees. For the $\mathrm{G} \bullet \mathrm{U}$ pair at the HF/6-31G ** optimized in Watson-Crick-Watson-Crick interactions, the $\mathrm{NH} \cdots \cdot \mathrm{O}$ angle is 176,1 degrees $^{21}$.

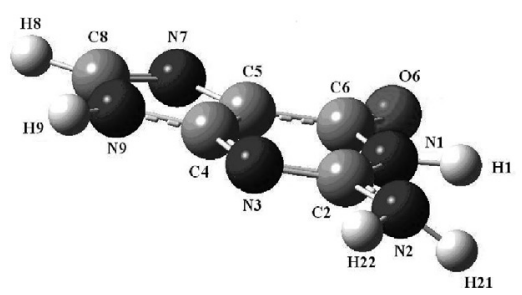

Guanine (I)

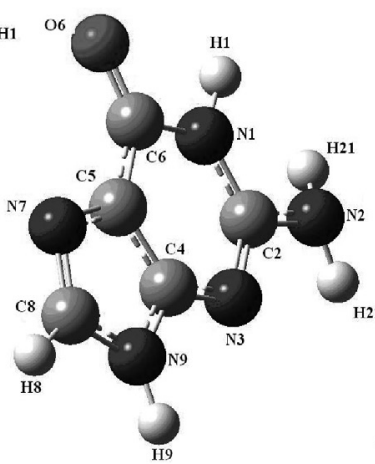

Guanine (II)

Fig. 2: The non-Watson-Crick Guanine(I)-Guanine(II)

Interesting is the fact that both bases in the $\mathbf{G}(\mathbf{I})-\mathbf{G}(\mathbf{I I})$ pair are not planar unlike what is observed in the rest of the optimized structures of the nonWatson-Crick pairs studied by our group at the $\mathrm{HF} / 6-31 \mathrm{G}(\mathrm{d}, \mathrm{p})$.

The direction of cis to the glycosidic link, defines in the majority of base pairs non-Watson-Crick, a large negative propeller twist, which turns out to be close to zero in base pairs with trans orientation ${ }^{22}$. These results are in agreement with those obtained in the present work.
Table 1: Bond distances $(\AA)$ and angles (grades) for the isolated and pairing bases.

\begin{tabular}{lll}
\hline Bond distances & $\mathrm{G}$ & $\mathrm{G}(\mathrm{I})-\mathrm{G}(\mathrm{II})$ Pair \\
\hline $\mathrm{N}_{1}-\mathrm{H}_{1}$ & 1.013 & $1.022 / / 1.014$ \\
$\mathrm{C}_{2}-\mathrm{N}_{2}$ & 1.371 & $1.3697 / / 1.369$ \\
$\mathrm{C}_{2}-\mathrm{N}_{1}$ & 1.377 & $1.3703 / / 1.374$ \\
$\mathrm{~N}_{2}-\mathrm{H}_{21}$ & 1.010 & $1.019 / / 1.001$ \\
$\mathrm{~N}_{2}-\mathrm{H}_{22}$ & 1.011 & $1.010 / / 1.010$ \\
$\mathrm{~N}_{3}-\mathrm{C}_{2}$ & 1.312 & $1.321 / / 1.316$ \\
$\mathrm{C}_{4}-\mathrm{N}_{3}$ & 1.358 & $1.354 / / 1.354$ \\
$\mathrm{C}_{5}-\mathrm{C}_{4}$ & 1.395 & $1.395 / / 1.393$ \\
$\mathrm{C}_{6}-\mathrm{C}_{5}$ & 1.441 & $1.442 / / 1.433$ \\
$\mathrm{C}_{6}-\mathrm{O}_{6}$ & 1.218 & $1.222 / / 1.226$ \\
$\mathrm{C}_{8}-\mathrm{N}_{7}$ & 1.308 & $1.308 / / 1.310$ \\
$\mathrm{C}_{8}-\mathrm{N}_{9}$ & 1.385 & $1.385 / / 1.381$ \\
$\mathrm{C}_{8}-\mathrm{H}_{8}$ & 1.081 & $1.082 / / 1.081$ \\
$\mathrm{~N}_{9}-\mathrm{H}_{9}$ & 1.009 & $1.008 / / 1.009$ \\
$\mathrm{C}_{5}-\mathrm{N}_{7}$ & 1.382 & $1.384 / / 1.382$ \\
\hline
\end{tabular}

Table 2: Bond distances $(\AA)$ and angles (grades) for the atoms involved in hydrogen bonding.

in $\mathbf{G}(\mathbf{I})-\mathbf{G}(\mathrm{II})$

Bond distances

$\begin{array}{ll}\mathrm{H}_{1} \ldots \mathrm{O}_{6} & 1.925 \\ \mathrm{~N}_{7} \ldots \mathrm{H}_{21} & 2.146\end{array}$

Bond angles

$\mathrm{N}_{1}-\mathrm{H}_{1} \ldots \mathrm{O}_{6} \quad 179.05$

$\mathrm{N}_{2}-\mathrm{H}_{21} \ldots \mathrm{N}_{7}$

Non-bonded distances

$\begin{array}{lc}\mathrm{O}_{6} \ldots \mathrm{N}_{1} & 2.948 \\ \mathrm{~N}_{2} \ldots \mathrm{N}_{7} & 3.1488\end{array}$

The energy of interaction (DE) of the G(I)-G(II) pair calculated here is ca. $-10.7 \mathrm{kcal} / \mathrm{mol}$, in good agreement with the valued of $\mathbf{D E}$ obtained, at the same level of theory for the $\mathbf{G}(\mathbf{I})-\mathbf{G}(\mathbf{I I})$ pair in trans orientation and when Watson Crick and Hoogsteen edges interact $(-17.58 \mathrm{Kcal} / \mathrm{mol})^{4}$. Bhattacharyya et $\mathrm{al}^{3}$ reported a value of $-16.70 \mathrm{kcal} / \mathrm{mol}$ for the latter pair at $\mathrm{HF} / 6-31 \mathrm{G} * *$. The energies of interaction $(-22.9 \mathrm{kcal} / \mathrm{mol})^{20}$ calculated at $\mathrm{HF} / 6-31 \mathrm{G} * *$ level and corrected for BSSE are in agreement with the abundance with which it is possible to find at the $\mathrm{G}=\mathrm{C}$ pair within both DNA and RNA. The energies calculated for the non-Watson-Crick pairs $\mathrm{G} \bullet \mathrm{U}$ and $\mathrm{U} \bullet \mathrm{U}$ at the same level of theory are -13.6 and $-8.75 \mathrm{kcal} / \mathrm{mol}$ respectively ${ }^{21}$. The frequency with which it is possible to find the $\mathrm{G} \bullet \mathrm{U}$ pair in the t-RNA is high in relation to the $\mathrm{U} \bullet \mathrm{U}$ pair and similar to the pair $\mathrm{G}=\mathrm{C}$. Although the interaction of energy calculated for the pair reported here is favorable for the formation of the respective hydrogen bonds between two molecules of guanine, one cannot correlated this value with frequency of occurrence within the nucleic acids.

Table 3: Partial atomic charges (isolated guanine and in GG pair).

\begin{tabular}{lcc}
\hline & Guanine isolated & Guanine in the pair GG \\
N3 & $-0,58$ & $-0,58$ \\
N7 & $-0,47$ & $-0,52$ \\
O6 & $-0,50$ & $-0,52$ \\
H1 & $+0,27$ & $+0,31$ \\
H21 & $+0,27$ & $+0,30$ \\
H22 & $+0,27$ & $+0,27$ \\
\end{tabular}

The charge distribution inside the heterocycles is relevant parameters to be considered in the study of complementary bases since the interaction energies depend on the partial charges of the atoms. In general, it has been observed that the atoms involved in the hydrogen bonding adopt small additional charges upon pairing ${ }^{23}$. It is also observed that $\mathrm{O} 6$ in the pair presents less charge than in the Guanine-Uracil pair, thought N7 becomes more negative in the present case as compared with G-U pair. 


\section{CONCLUSIONS}

1. Optimized Structure at ab initio level using DFT with B3LYP functional and a basis set of $6-31 \mathrm{G}(\mathrm{d}, \mathrm{p})$, shows that both nitrogen bases inside the GG pair is not co-planar and are characterized by a large negative propeller twist. This characteristic is generally associated with the pairs of pairs in direction cis.

2. The formation of the respective hydrogen bonds between two molecules of Guanine is energetically favorable.

3. The energy of interaction is similar to GG no par-Watson-Crick G $\bullet U$. However, it was not found within the nucleic acids with the same frequency as the latter.

\section{ACKNOWLEDGMENT}

This work was partially supported by the Direction of Research of Universidad Austral de Chile through Project DID S-2004-66 and Universidad de Concepción by an operating grant $\mathrm{N}^{\circ}$ 208.021.027-1.

\section{REFERENCES}

1.- T. Hermann, E. Westhof, Chem.Biol. 6, 335, (1999).

2.- N. Leontis., K. Stombaugh, E. Westhof, Nucleic Acids Res. 30, 3497, (2002).

3.- D. Bhattacharyya, S. Koripella, A. Mitra, V. Rajendran, B. Sinha, J. Biosci., 32, 809, (2007).

4.- A. Roy, S. Panigrahi, M. Bhattacharyya, D. Bhattacharyya, J. Phys. Chem., B112, 3786, (2008)

5.- A. Lescoute, E. Westhof, Nucleic Acids. Res., 34, 6587, (2006)

6.- H. Sun, R. Bennett, N. Maizels, Nucleic Acids Res., 27, 1978, (1999).

7.- K. Nakatani, A. Kobori, H. Kumasawa, I. Saito, Bioorg. Med. Chem. Lett., 14, 1105, (2004).
8.- R. Wells, FASEB J. 22, 1625, (2008).

9.- I. Bang, Bioch. Ztschr. 26, 293, (1910).

10.- J. Williamson, Annu. Rev. Biophys. Biomol. Struct. 23, 703, (1994)

11.- J. Dai, M. Carver, D. Yang, Biochimie. 90, 1172, (2008)

12.- A. Tood, M. Johnston, S. Neidle. Nucleic Acids Res. 33, 2901, (2005)

13.- S. Burge, G. Parkinson, P. Hazel, A. Todd, S. Neidle. Nucleic Acids Res. 34, 5402, (2006)

14.- S. Neidle, G. Parkinson, Biochimie, 90, 1184, (2008)

15.- J. Sponer, J. Leszczynski, P. Hobza, J. Biomolec. Struct. Dyn. 14, 117, (1996).

16.- M. J. Frisch, G.V. Trucks, H.B. Schlegel, M.A. Scuseria, M.A. Robb, J.R. Cheeseman, V.G. Zakrzewski, J.A. Montgomery Jr., R.E. Stratman, J.C. Burant, D. Dapproch, J.M. Millan, A.D. Daniels, K.N. Kudin, M.C. Stain, O. Farkas, J. Tomasi, V. Barone, M. Cossi, R. Cammi, B. Menucci, C. Pomelli, C. Adamo, S. Clifford, J. Ochterski, G.A. Peterson, P.Y. Ayala, Q. Cui, K. Morokuma, D.K. Malick, A.D. Rabuck, K. Raghavachari, J.B. Foresman, J. Cioslowski, J.B. Ortiz, A.G. Baboul, B.B. Stefanov, G. Lui, A. Liashenko, P. Piskorz, I. Komaromi, R. Gomperts, R.L. Martin, D.J. Fox, T. Keith, M.A. Al-Laham, C.Y. Peng, A. Nanayakkara, C. Gonzalez, M. Chalacombe, P.M.W. Gill, B. Johson, W. Cheng, M.W. Wong, J.L. Andres, M. Head-Gordon, E.S. Repogle, J.A. Pople, Gaussian 98, revision A7, Gaussian Inc., Pittsburg, PA., USA, 1998.

17.- A. D. Becke, J. Chem. Phys. 98, 5648, (1993),

18.- C. Lee, W. Yang, R. G. Parr, Phys. Rev. B, 37, 785, (1988).

19.- S. Boys, F. Bernardi, Mol. Phys. 19, 553, (1970).

20.- J. Contreras, S. Madariaga, Bioorg. Chem. 31, 367, (2003).

21.- S. Madariaga, J. Contreras, C. Seguel. J. Chil. Chem. Soc. 50, 435, (2005).

22.- S. Mukherjee, M. Bansal, D. Bhattacharyya, J. Comput. Aided Mol. Des., 20, 629, (2006).

23.- S. Jiang, G. Raghunathan, K. Ting, J. Xuan, R. Jernigan, J. Biomol. Struct. Dyn. 12, 367, (1994). 